\title{
A comparative assessment of two tools designed to support patient safety culture in UK general practice
}

Ian Litchfield ${ }^{1 *}$, Kate Marsden², Lucy Doos ${ }^{3}$, Katherine Perryman $^{4}$, Anthony Avery ${ }^{2}$ and Sheila Greenfield ${ }^{1}$

\begin{abstract}
Background: The NHS has recognised the importance of a high quality patient safety culture in the delivery of primary health care in the rapidly evolving environment of general practice. Two tools, PC-SafeQuest and MapSaf, were developed with the intention of assessing and improving patient safety culture in this setting. Both have been made widely available through their inclusion in the Royal College of General Practitioners' Patient Safety Toolkit and our work offerss a timely exploration of the tools to inform practice staff as to how each might be usefully applied and in which circumstances. Here we present a comparative analysis of their content, and describe the perspectives of staff on their design, outputs and the feasibility of their sustained use.
\end{abstract}

Methods: We have used a content analysis to provide the context for the qualitative study of staff experiences of using the tools at a representative range of practices recruited from across the Midlands (UK). Data was collected through moderated focus groups using an identical topic guide.

Results: A total of nine practices used the PC-SafeQuest tool and four the MapSaf tool. A total of 159 staff completed the PC-SafeQuest tool 52 of whom took part in the subsequent focus group discussions, and 25 staff completed the MapSaf tool all of whom contributed to the focus group discussions. PC-SafeQuest was perceived as quick and easy to use with direct questions pertinent to the work of GP practices providing useful quantitative insight into important areas of safety culture. Though MaPSaF was more logistically challenging, it created a forum for synchronous crosspractice discussions raising awareness of perceptions of safety culture across the practice team.

Conclusions: Both tools were able to promote reflective and reflexive practice either in individual staff members or across the broader practice team and the oversight they granted provided useful direction for senior staff looking to improve patient safety. Because PC SafeQuest can be easily disseminated and independently completed it is logistically suited to larger practice organisations, whereas the MapSaf tool lends itself to smaller practices where assembling staff in a single workshop is more readily achieved.

Keywords: General practice, Patient safety, Safety culture, Health service delivery

\footnotetext{
*Correspondence: I.Litchfield@bham.ac.uk

${ }^{1}$ Institute of Applied Health Research, College of Medical and Dental

Sciences, University of Birmingham, Birmingham, UK

Full list of author information is available at the end of the article
}

(C) The Author(s) 2021. Open Access This article is licensed under a Creative Commons Attribution 4.0 International License, which permits use, sharing, adaptation, distribution and reproduction in any medium or format, as long as you give appropriate credit to the original author(s) and the source, provide a link to the Creative Commons licence, and indicate if changes were made. The images or other third party material in this article are included in the article's Creative Commons licence, unless indicated otherwise in a credit line to the material. If material is not included in the article's Creative Commons licence and your intended use is not permitted by statutory regulation or exceeds the permitted use, you will need to obtain permission directly from the copyright holder. To view a copy of this licence, visit http://creativecommons.org/licenses/by/4.0/. The Creative Commons Public Domain Dedication waiver (http://creativeco mmons.org/publicdomain/zero/1.0/) applies to the data made available in this article, unless otherwise stated in a credit line to the data. 


\section{Introduction}

The concept of organisational safety culture first emerged from the nuclear industry in the mid-1980s and is defined by the level of commitment of an organisation and its employees toward "values, attitudes, and patterns of behaviour" to successfully manage and improve health and safety $[1,2]$. Since then understanding and promoting safety culture has been accepted as a challenging yet critical process across a number of high risk industrial sectors including aviation mining [3-5] and more recently healthcare [6-8]. To be effective this culture requires the workforce share perceptions of the importance of safety and also engage in generating ideas that can reduce 'risk, accidents and ill health' [9-12]. In industry several approaches have been developed to examine and promote safety culture including checklists [13, 14] and competency assessments [15].

Over the last decade the United Kingdom's (UK) National Health Service (NHS) has recognised the importance and challenges of developing a culture that prioritises and maximises the safety of the care it provides [16-19]. Facilitating this within such a diverse organisation is a difficult task, particularly so in primary care where a diverse range of general practices are expected to provide equitable and consistently safe care for their patients despite evolving and complex demands on their services [20,21]. This has been highlighted by the recent pandemic [22-26] where significant changes in care provision were introduced without the recommended period of consultation, implementation, and evaluation [27, 28].

One way to mitigate the risks to patient safety incurred by the sudden introduction of new methods of working is by providing the means for the entire practice team to reflect on the care they provide [29-31]. Two tools have been made available through the Royal College of General Practitioners (RCGP) website as part of their patient safety toolkit $[32,33]$ that can readily fulfil this function $[34,35]$. They both explore a number of key domains of patient safety culture but utilise two very different approaches with varying implications for the time and resource required for their completion and the way in which their outputs are described and presented; the NHS Education for Scotland's Primary Care Safety Questionnaire (PC-SafeQuest) uses a confidential online questionnaire [36] and the Manchester Patient Safety Framework (MaPSaF) involves a moderated workshop attended by a range of practice staff [35].

The use of either tool is not mandated but implemented at the discretion of individual practices. The work we present here is positioned to help General Practitioners (GPs) and other senior staff make an informed judgement on which of these tools might best suit their organisation. To help support this decision we conducted a comparative content analysis of each tool which provides context for a qualitative exploration of the experiences of staff that had used both [37]. By combining these complementary methodological approaches our research intended to provide timely and valuable insight into how these tools might be most appropriately used and the practical benefits they offer in support of patient safety in primary care practices.

\section{Method \\ Design}

The study consisted of two phases; the first phase consisted of a comparative content analysis where both tools were assessed against ten previously identified criteria considered to be key in the effective assessment of patient safety culture [38, 39]; in the second phase both tools were introduced to the same general practice surgeries and the experiences of staff that used each tool were captured via separate moderated focus groups. Some staff would have taken part in two focus groups having used both tools. The data was analysed using recognised measures associated with successful implementation.

\section{Settings}

A total of nine practices of varying characteristics were recruited from across three clinical commissioning groups (CCGs) within the central region of the UK; North Staffordshire, Moorlands and Shropshire, and Wolverhampton.

\section{Participants/recruitment}

Practices were recruited as part of the broader Patient Safety Toolkit (PST) project [40] a process facilitated by the National Institute for Health Research (NIHR) Clinical Research Network (CRN) [41] who contacted every practice across all CCGs, describing the premise of the PST and inviting each to participate. Those practices that expressed an interest were visited by a member of the study team (KM, LD) to discuss the practicalities and benefits of their involvement and ultimately nine were purposively selected [42] to create a sample incorporating a range of list sizes, and socio-economic environments representative of the range of practices found in English primary care [40]. The sample size considered appropriate to provide practical insight into the use of each tool and inform the future development of the patient safety toolkit [40].

\section{The tools}

\section{PC-SafeQuest safety climate survey}

PC-SafeQuest was designed and validated by NHS Education for Scotland to grant senior clinical and management staff an understanding of how their colleagues 
perceive and promote patient safety within their organisation [36]. It consists of on an online survey issued to each member of practice staff containing 30 questions presented within six safety-related domains where staff present their answer on a Likert scale [36]. The scores for each domain are compiled and a report generated for the practice which can be compared over time against previous practice scores or, via the PC-SafeQuest portal, with similar practices [36]. The key characteristics of PC-SafeQuest are summarised in Table 1.

\section{Manchester Patient Safety Framework (MaPSaF)}

The MaPSaF tool creates a forum for team-based reflection on multiple dimensions of patient safety [35]. First asking pairs of participants to evaluate their practice within one to five levels of organisational development across nine domains of safety culture, based on Westrum's theory which classifies organisations dependent upon the degree of unity and motivation that staff share with their organisation's over-arching goals [35, 43, 44]. The tool is facilitated by a trained moderator during a workshop which can last between 1 and $2 \mathrm{~h}$ and accommodate up to 12 staff [45]. The key characteristics of MapSaf are summarised in Table 1.

\section{Data collection}

\section{Phase one: content analysis}

We accessed and analysed the content of both tools alongside the information supporting their use via the Patient Safety Toolkit (PST) portal accessed through Royal College of General Practitioner's website [32, 36, 45].

\section{Phase two: qualitative assessment}

Focus groups were chosen to gather staff perspectives because of their ability to promote challenge and produce consensus [46] as opposed to isolating opinions specific to a certain job title or role [47], reflecting the aim of the tools to promote collective reflection. The decision to anonymise participant identity was made to elicit totally honest comments regarding the efficacy of the tools and specific examples of how they uncovered culture related safety incidents within individual practices [48]. We were also wary of the vicarious disclosure of participant identity that can occur in groups where individuals are already known to one another, which might have adversely impacted the working relationships within the practices involved and the intended arc of the PST project [49]. The MapSaf focus groups were convened immediately following the use of the tool, with the same participants. The PC-SafeQuest focus groups were convened between approximately 6 and 8 weeks after the tool was completed and results were returned to the practice.

Ethical approval was obtained from East MidlandsNottingham 1 Research Ethics Committee - REC/ REF-13/EM/0258 15 July 2013 for all organisations involved. All methods were performed in accordance with the relevant guidelines and regulations in line with this approval. All participants were over 18 and provided signed consent prior to the beginning of each focus group. The same semi-structured topic guide was used for MapSaf and PC-SafeQuest and contained questions on staff expectations of the tool, their experience of its application including its ease of

Table 1 Key characteristics of PC-SafeQuest and MaPSaF patient safety tools

\begin{tabular}{|c|c|c|}
\hline & PC-SafeQuest & MaPSaF \\
\hline Aim & $\begin{array}{l}\text { To survey patient safety climate and inform patient safety } \\
\text { improvement. }\end{array}$ & $\begin{array}{l}\text { To facilitate improvements in safety culture through con- } \\
\text { structive reflective practice. }\end{array}$ \\
\hline Facilitated & $\begin{array}{l}\text { Self-completed with a summary report automatically gener- } \\
\text { ated. }\end{array}$ & Led by an independent moderator. \\
\hline Level of anonymity & Anonymous and completed confidentially. & Group members known to each other. \\
\hline Number of participants & All staff in the practice. & Up to 12 members of practice staff. \\
\hline Staff groups involved & All grades of staff & All grades of staff \\
\hline Format & Online questionnaire & Workshop and group discussion \\
\hline Structure of the tool & $\begin{array}{l}\text { A total of } 30 \text { questions within } 6 \text { domains. } \\
\text { Completed questionnaires are collated for each practice } \\
\text { scores produced for each domain in a final report pro- } \\
\text { duced by PC-SafeQuest. }\end{array}$ & $\begin{array}{l}\text { An evaluation sheet consisting of nine domains with the } \\
\text { option of selecting one of } 5 \text { levels of'maturity' for each. } \\
\text { This is to be completed by each participant during the work- } \\
\text { shop and the results to be discussed as a group. }\end{array}$ \\
\hline Outputs & $\begin{array}{l}\text { Generation of report where scores can be compared with } \\
\text { previous reports from that practice or practices of similar } \\
\text { characteristics. }\end{array}$ & $\begin{array}{l}\text { Discussion of evaluation sheet results as part of workshop } \\
\text { identifies any areas that might need to be looked at. }\end{array}$ \\
\hline Time to complete & $\begin{array}{l}10 \text { min for online questionnaire. (The time taken by senior } \\
\text { staff to assimilate and act on this data was not formally } \\
\text { recorded). }\end{array}$ & $60-120 \mathrm{~min}$ \\
\hline
\end{tabular}


use, and what if any action has or would be taken as a result. These questions are presented in Table 2. All focus group discussions were moderated by an experienced Research Fellow (LD) who strived to ensure that all voices were heard, digitally recorded, professionally transcribed and the data ultimately managed within NVivo 10.

\section{Analysis \\ Phase one: content analysis}

We used a comparative content analysis $[50,51]$ where both tools were interrogated for the presence of the ten key dimensions of an effective patient safety culture tool $[38,39]$. In summary these were; 1) Leadership 2) Safe systems and processes 3) Resources, including training and equipment 4) Interpersonal relationships, including teamwork and collaboration 5) Communication, including raising issues with senior staff 6) Learning from mistakes 7) Characteristics of staff, including workload and stress 8) Awareness and priority of patient safety 9) Safety incentives and rewards and 10) Safety issues witnessed and reported.

\section{Phase two: qualitative assessment}

For the qualitative data a post-hoc deductive analysis [52] was conducted where transcripts of the group discussions were searched for text relating to three characteristics (acceptability, appropriateness, and feasibility) regarded as instrumental to the early stages of successful implementation and predictive of sustained adoption [37, 53] based on Roger's theory of diffusion [37]. These are further defined alongside their theoretical basis in Table 3. In undertaking the analysis, each of IL, KM, KP, and SG independently reviewed a sample of the transcripts for data relating

Table 2 Questions for focus group

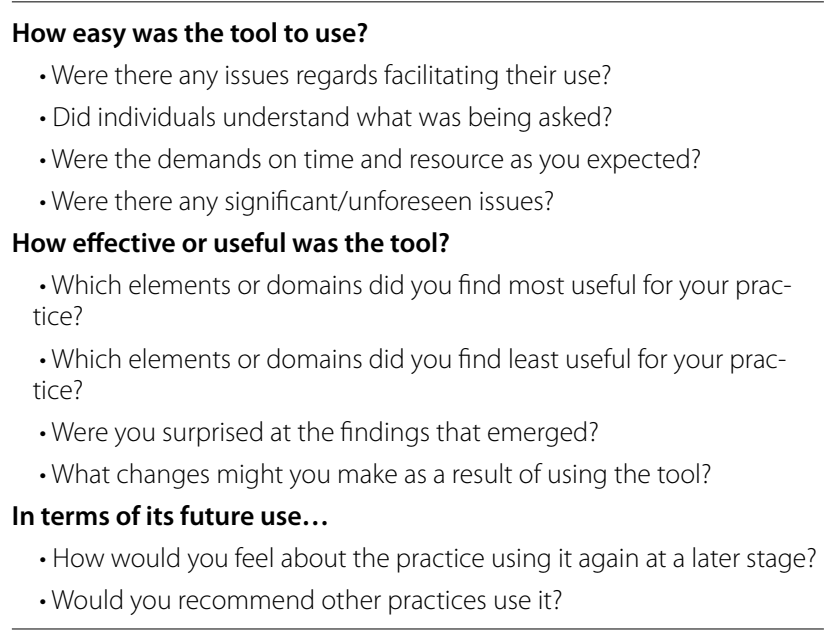

to the three characteristics and decisions regarding where text should be placed were discussed and consensually decided. The remainder of the analysis was undertaken by IL with the final interpretation agreed by all authors.

\section{Results}

Phase 1: content analysis

Table 4 illustrates the similarities and differences between the content of the two tools in comparison with the ten criteria identified from the most recent and comprehensive review of tools of safety culture assessment $[38,39]$. Out of the ten criteria, nine were covered by at least one of the tools with the exception of "Other means of prioritising safety (such as through rewards and incentives)" i.e. the presence of or adherence to initiatives intended to improve or promote patient safety which neither tool addressed. Both tools explored "The quality of interpersonal relationships (such as teamwork, collaboration within and across units)" and "Communication, particularly about safety, including perceptions of being able to report and speak up" describing the ability to communicate about safety and freely raise patient safety concerns. Areas of difference were that PC-SafeQuest specifically asked questions regarding "Leadership, particularly the support of safe practice" and the "Systems, procedures and processes exist that normalise or enshrine patient safety, or which are adhered to" and MapSaf explored the degree to which "Resources for safety (such as staffing, equipment, training)" were made available for patient safety, the "focus on learning from mistakes, responding and improving systems", and the investigations of "Actual safety issues witnessed reported".

\section{Phase II: qualitative assessment Practice characteristics}

Of the nine practices that were recruited patient list sizes ranged from 919 to 12,246 patients and the number of GPs from three to seven. One was a teaching practice and two were dispensing practices and the characteristics of all participating practices are summarised in Table 5. All nine practices totalling 159 staff completed the PCSafeQuest tool, four practices used the MaPSaF as after recruitment five practices reported their inability to incorporate an additional training session within the time-frame of the study. A total of thirteen focus groups were convened; nine discussed the PC-SafeQuest tool and four the MapSaf tool involving 54 and 25 participants respectively and they lasted between 14 and $35 \mathrm{~min}$. Participants included GPs, nurses, and administrators and the job titles of participants within each focus group is summarised in Table 6. 
Table 3 Key implementation outcomes, their definition and theoretical basis

\begin{tabular}{|c|c|c|}
\hline Implementation outcome & Definition & Theoretical basis \\
\hline Acceptability & $\begin{array}{l}\text { Satisfaction with various aspects of the innovation (e.g. } \\
\text { content, complexity, comfort, delivery, and credibility). }\end{array}$ & $\begin{array}{l}\text { Concerning the complexity and relative advantage of the } \\
\text { intervention where "Complexity" is a measure of the } \\
\text { degree to which an innovation is perceived as difficult } \\
\text { to understand and use [54] and relative advantage is The } \\
\text { degree to which an innovation is perceived as better } \\
\text { than the idea it supersedes. }\end{array}$ \\
\hline Appropriateness & $\begin{array}{l}\text { Perceived fit; relevance; compatibility; suitability; usefulness; } \\
\text { practicability }\end{array}$ & $\begin{array}{l}\text { A measure of the degree to which an innovation is } \\
\text { perceived as being compatible with existing values, past } \\
\text { experiences, and the needs of potential adopters [54] }\end{array}$ \\
\hline Feasibility & $\begin{array}{l}\text { Actual fit or utility; suitability for everyday use; including the } \\
\text { ease with which it can be piloted or trialled. }\end{array}$ & $\begin{array}{l}\text { Alongside the concept of compatibility, feasibility also } \\
\text { includes Roger's concept of trialability i.e. the degree to } \\
\text { which the innovation may be piloted and modified [54]. }\end{array}$ \\
\hline
\end{tabular}

Qualitative data The qualitative data is presented below within the domains described previously relevant to early implementation and indicative of longer-term adoption; Acceptability, Appropriateness, and Feasibility $[37,55]$.

\section{Acceptability}

Participants described attitudes toward the design and content of both tools and the relative simplicity with which they can be used.

PC-SafeQuest It was felt that the language of the survey questions was straightforward and easy to comprehend, representing concepts that were directly relevant to the systems and processes practices deployed.

"Well, they were questions that you actually could give an answer to. It was meaningful - you needed to answer, that they were relevant to the surgery, to you in your role, to you and your workmates, you and the practice. It was short, to the point..." Practice-08, Female

The PC-SafeQuest survey was designed to be completed independently and anonymously and participants appreciated the freedom this granted to answer honestly.

"I think you get a probably more honest answer when people fill in an anonymised questionnaire in their own time, when they've got time to think about it. You're not pressured by a group environment, by time, by peer pressure." Practice-08, Male

Some of the questions in the survey were phrased in the negative to disrupt the "response-order effect" where responders adopt a pattern in answering scaled questions [56]. This did however leave some confused. As one participant at Practice-07 described,

\section{"Because once or twice I found myself - I knew what the answer I wanted was but then I went back and realised I'd done my scoring the wrong way round, it was completely at the other end!" Practice-07, Female}

MaPSaF Participants felt that prior sight of the tool evaluation sheet that was used to begin the process of group reflection [45] could have helped them shape a more accurate response.

\section{"Might have been nice to have had this before and actually read it and digested it because it's a lot to take in." Practice-01, Female}

This evaluation sheet details a series of patient safety related concepts [45], and some felt the prescriptive nature of the text failed to accurately reflect processes specific to their individual practice. As one participant at Practice-07 explained this left them unsure as to how accurately they had portrayed their patient safety culture.

\section{"We marked ourselves down on some things because of the wording, like you were saying 'elec- tronic', or 'the patient involvement in the training' and all that, and I think it's the wording around those-because it shouldn't reflect a mark down really for us-should it? Because we're just doing it in a different format that better suits the practice?" Practice-07, Female}

The MapSaf tool originated in industry [35] and some felt the language and terminology remained redolent of its 


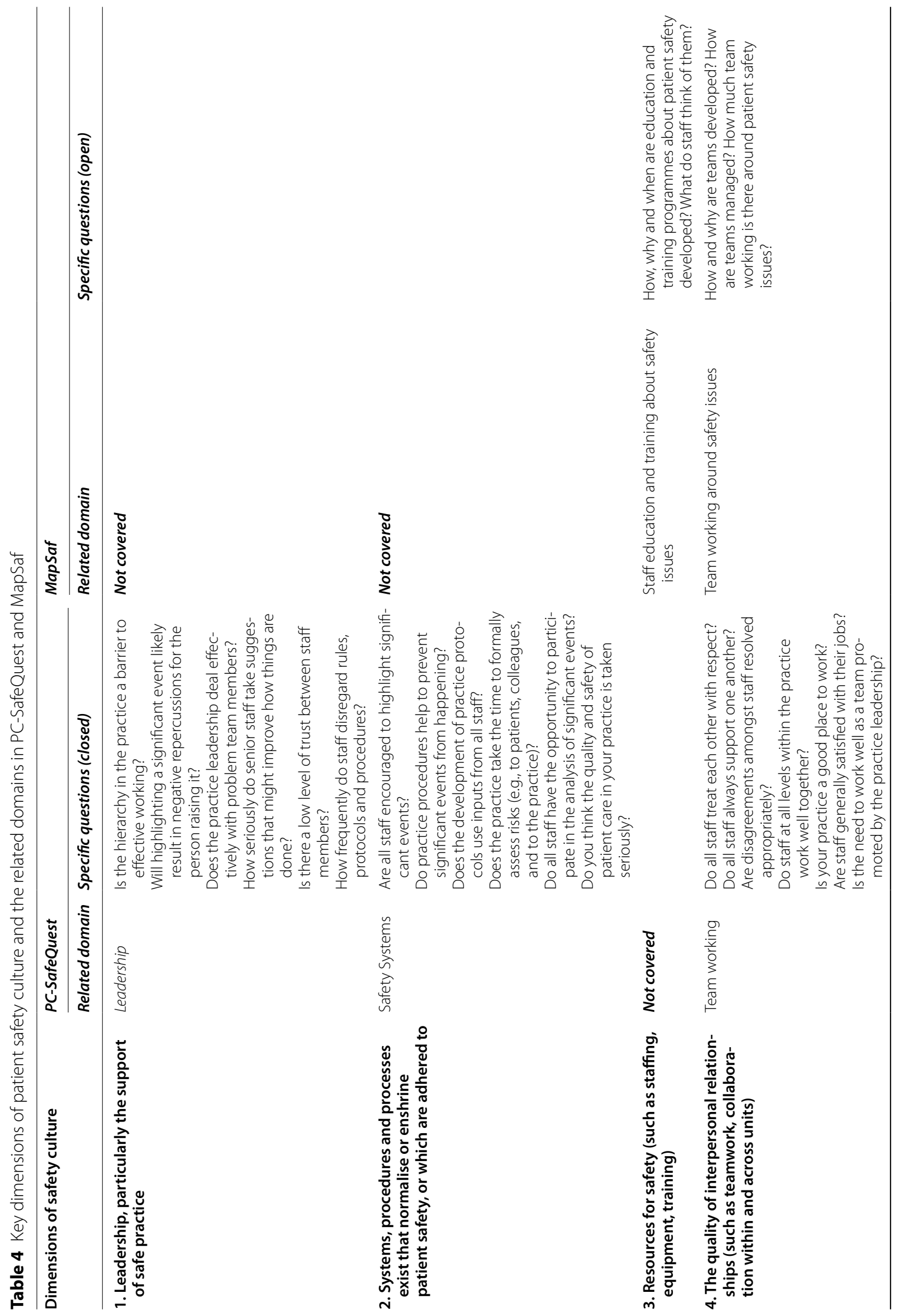




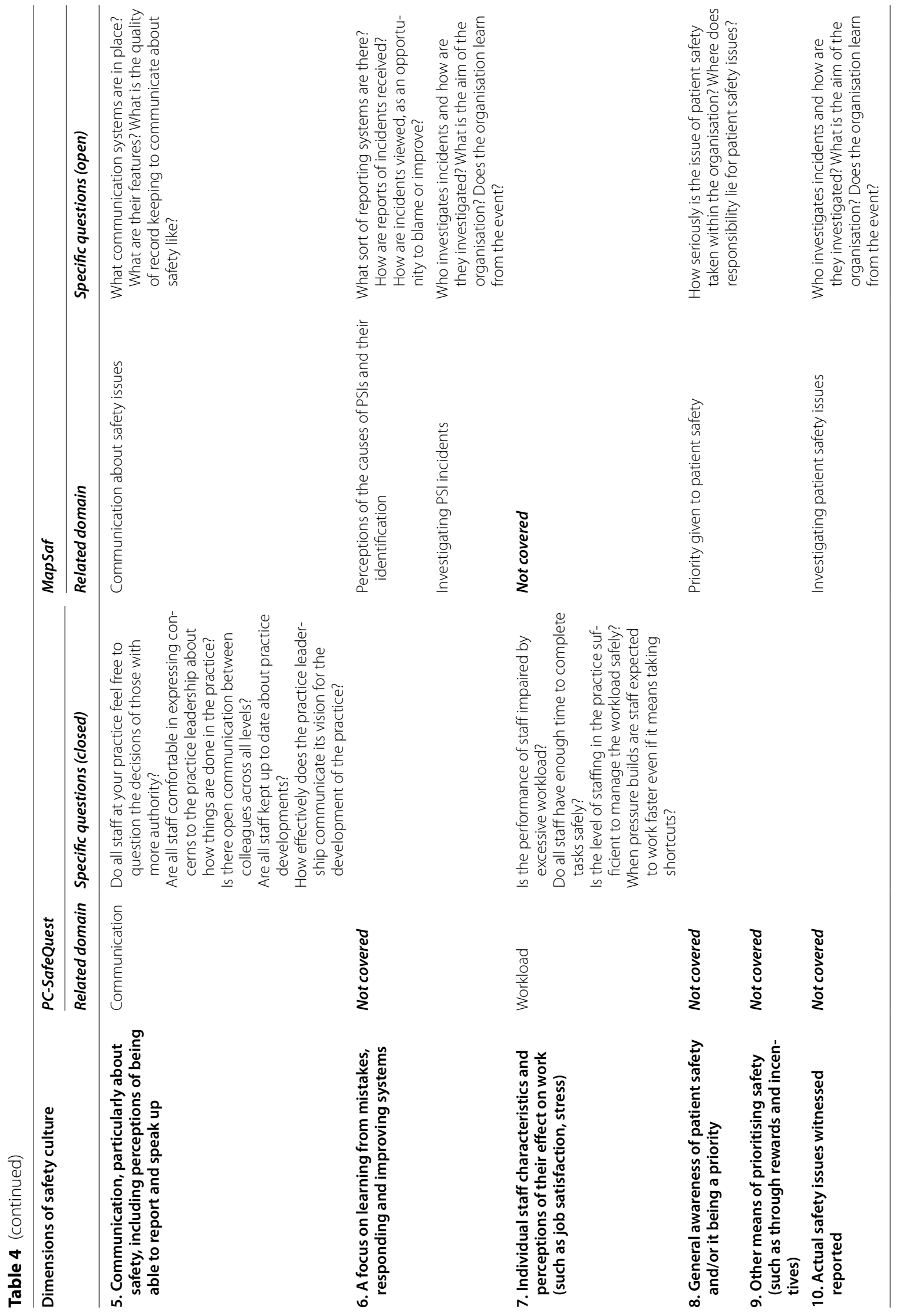




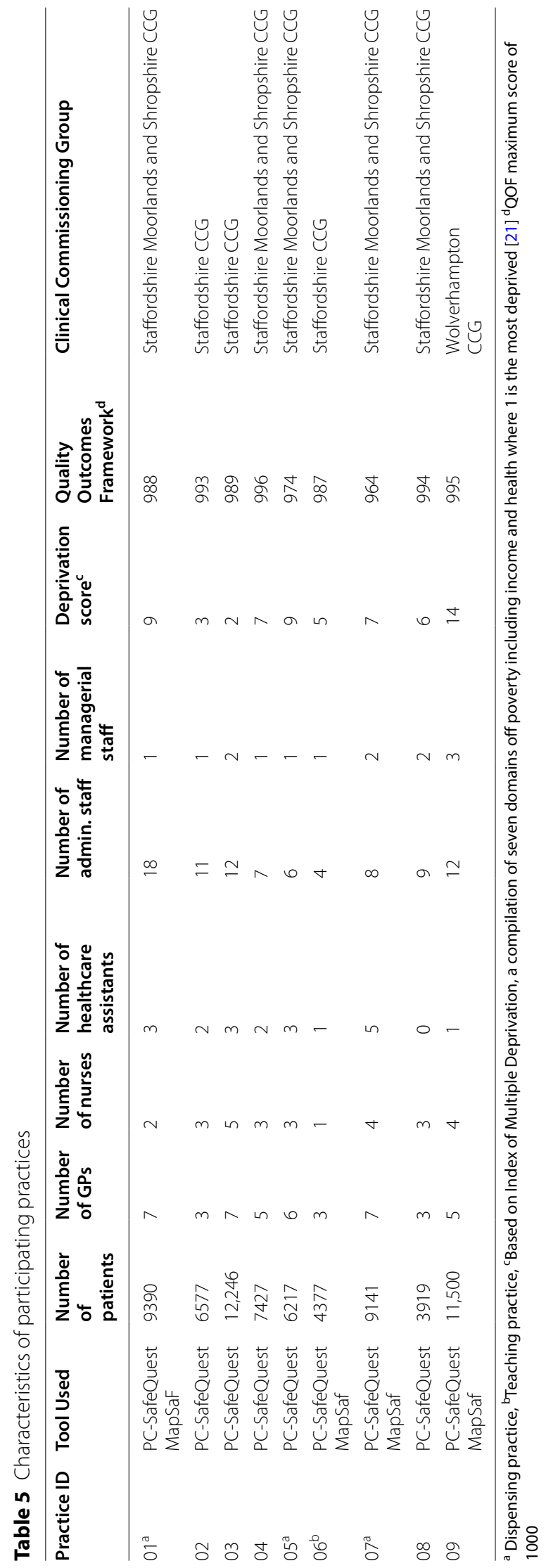


Table 6 Job role of those interviewed at each practice

\begin{tabular}{|c|c|c|c|c|c|c|c|c|c|c|c|c|c|c|c|c|c|c|c|c|}
\hline & \multicolumn{2}{|c|}{ Practice-01 } & \multicolumn{2}{|c|}{ Practice-02 } & \multicolumn{2}{|c|}{ Practice-03 } & \multicolumn{2}{|c|}{ Practice-04 } & \multicolumn{2}{|c|}{ Practice-05 } & \multicolumn{2}{|c|}{ Practice-06 } & \multicolumn{2}{|c|}{ Practice-07 } & \multicolumn{2}{|c|}{ Practice-08 } & \multicolumn{2}{|c|}{ Practice-09 } & \multicolumn{2}{|c|}{ Total $n$} \\
\hline & $M S^{\mathrm{a}}$ & $S Q^{a}$ & MS & $S Q$ & MS & $S Q$ & MS & $S Q$ & $M S$ & $S Q$ & MS & $S Q$ & $M S$ & $S Q$ & MS & $S Q$ & MS & $S Q$ & $M S$ & $S Q$ \\
\hline GP & 2 & 1 & & 1 & & & & 1 & & 1 & 2 & 2 & 2 & 2 & & 1 & 2 & 2 & 8 & 11 \\
\hline PM & & 1 & & 1 & & 1 & & 1 & & 1 & & & 1 & 1 & & 1 & 1 & 1 & 2 & 8 \\
\hline HCA & & & & & & 1 & & & & & 1 & 1 & & & & & & & 1 & 2 \\
\hline Pharm. & & & & & & & & & & & & & 1 & & & & & & 1 & \\
\hline P Nurse & 1 & & & 1 & & 1 & & & & & 1 & 1 & & & & & & & 2 & 3 \\
\hline Admin & 3 & 3 & & 5 & & 3 & & 5 & & 4 & 4 & 4 & 2 & 2 & & 2 & 2 & 2 & 11 & 30 \\
\hline Total & 6 & 5 & & 8 & & 6 & & 7 & & 6 & 8 & 8 & 6 & 5 & & 4 & 5 & 5 & 25 & 54 \\
\hline
\end{tabular}

${ }^{\mathrm{a}}$ MS MapSaf, SQ PC-SafeQuest

industrial background and less pertinent to their experience of modern healthcare practice.

"It feels like it's come from business and I don't think it's made the transition has it from the business world? It does feel like a 'Shell' document still' Practice-05, Male

\section{Appropriateness}

Participants described the relative success with which the tools produced actionable outputs relevant to the way care was provided at their particular GP practice.

PC-SafeQuest The PC-SafeQuest produced outputs that could inform practice wide discussions. For example a participant at Practice-02 felt the report could provide structure to conversations about the various dimensions of safety.

"I think it would be quite useful for us... the outcome, you know, what answers came up could be discussed at a practice meeting when everybody's present, you know? Everybody can have their input and as an add-on to what we would ordinarily do at a practice meeting when we have significant events and all that sort of stuff... I think it would be useful to be used in conjunction with that." Practice-02, Female

At Practice 09 one participant felt that the ability of the tool to grant an oversight of different areas of practice operations was a useful attribute, enabling the development of a coherent plan for improving safety involving multiple aspects of service delivery.

"I think we would have to look at the feedback in different [staff] groups...and so work out 'how did that happen? Why have we got such different numbers?' But if actually the practice all came out with very much the same sort of things then you can do a development plan for your whole practice together. So I think it gives you a lot of information..." Practice-09, Female

MaPSaF MapSaf enabled synchronous and open discussion across staff groups and its ability to create a broader understanding of the experiences of colleagues fulfilling different roles was described.

\section{"Talking to someone from a different clinical area or organisational area was really important because it just gives you that chance to see that other viewpoint and think-'actually, yeah we might do it particularly well in our area but the rest of the organisation might be doing it really well!' and it gives you a chance to do that." Practice- 01, Male}

Having such cross-practice discussions moderated by a neutral arbitrator that enabled all attendees to have an equal voice was also recognised as a valuable characteristic of the tool.

"...you need an external facilitator that says - 'What made you say that?' and will actually say to somebody 'You've got licence to talk because I'm asking you!' " Practice 09, Female

\section{Feasibility}

Participants described the practicability of introducing the tool into regular or routine daily use, including the potential long-term benefits and the resources required.

PC-SafeQuest The quantitative output of PC-SafeQuest offered the opportunity for a temporal comparison with previous scores at the same practice. As one participant at Practice-09 opined, 
"It's good to give you a comparator isn't it? 'Where were we last year? Where are we now?' and 'Who thinks differently? How is it the clinicians see this different to the non-clinicians? Managers to nonmanagers?'” Practice-09 Female

Another strength that was cited as contributing to its continued use was the way its inclusivity (i.e. it was completed by the full range of practice staff) would help embed a safety culture throughout the practice team. As a participant in Practice -01 explained,

“...by involving everyone, you are just doing it as part of that 'embedding the culture' because it's everyone seeing that actually they're totally involved in it you know? It isn't just a clinician, everyone is doing their bit and their bit is important, so whatever you do to a patient is important and it's [all] part of it and I think that's really important, quite powerful actually!" Practice-01, Male

MaPSaF In considering the sustained uptake of MaP$\mathrm{SaF}$, the benefits of its thorough and detailed approach were recognised by a number of participants.

\section{"I think it helps you understand 'what do these things mean?' Because reading it makes you stop and think about 'What do I do? How many of these things have I glossed over?' So just reading in detail... it is learn- ing without even realising you're learning - so from that point of view I think the practice to be exposed to [it] is good..." Practice-08, Female}

However, another participant sounded a note of caution that though it offered valuable information its complexity would likely prove inhibitive to its future use.

"... it is probably an extremely good place to start because I think it's very comprehensive. I think the problem is it's far too wordy and far too comprehensive and I don't think it works well in this particular environment." Practice-07, Male

\section{Discussion}

\section{Summary of main findings}

Our comparative evaluation of the content and usability of the two tools specifically designed to assess patient safety culture in UK primary care that are supported by the RCGP [32] provides senior staff with the practical insight that enables them to make a more informed decision on which to use and when. It is particularly timely considering the impact on patient safety of the sudden and substantive changes to care and the working environment experienced in general practice [24, 57].

The content analysis revealed that neither tool assessed all ten of the recommended dimensions of safety culture though between them nine were covered with the exception being performance incentives. The qualitative data revealed how both tools were appreciated for their ability to offer practicable insights into patient safety culture and facilitate cross-practice reflection on the safety of the care their practices provided. The quantitative PC-SafeQuest tool was recommended for being straightforward in concept and practice. It could be completed quickly, independently, and remotely whilst still capturing relevant data. However the speed with which this these reports were discussed or acted upon was dependent upon the discretion of senior staff [36]. In contrast the qualitative MaPSaF tool possessed greater immediacy by enabling synchronous in-depth discussion amongst a range of staff; promoting challenge and exploring emergent issues, though it was reliant upon the potentially difficult task of gathering a range of staff at a single time and location for several hours [45].

\section{Strengths and limitations}

This is the first comparative evaluation of two tools specifically developed to explore patient safety culture in the UK primary care and the practices which took part in our study represented a range of patient populations and practice sizes with a broad mix of clinical and non-clinical staff contributing to the focus group discussions. It was decided to retain the anonymity of participants because of concerns about deductive disclosure in view of the comparatively small sample size though we acknowledge that by not including personal characteristics a degree of insight for the reader may be lost [48, 58]. The length of the focus groups might be considered relatively short yet this can be explained by consensual theory whereby the tight focus of the discussion and the experience of those involved reduces the length of the discussion yet still produces valuable data [59]. This data proved capable of fulfilling the dual aims of the work which were to support the development of a coherent patient safety toolkit as well as provide practical information to GPs and other senior practice staff on the utility and usability of both tools. Ultimately only four practices completed the MapSaf tool citing a lack of the necessary time and though this reduced the amount of feedback it did tally with the comments of those that used the tool around the prohibitive length of the workshop. 


\section{Comparison with existing literature}

Despite a long-standing and increasing awareness of the importance of patient safety and the tools created in its support $[60,61]$ the improvements witnessed in other settings had failed to materialise in primary care [62, 63] motivating the development of a comprehensive patient safety toolkit to tackle a range of issues [40]. In its compilation the need to address the importance of safety culture became apparent $[30,64]$ and two tools were identified to fulfil this requirement, PC-SafeQuest and MaPSaF. Both were specifically developed for use in the UK to enable the cultural underpinning of collaborative safety-conscious care $[36,65]$ and both promoted the inclusion of the wider practice team in shaping and fulfilling practice objectives, strategies, and processes relating to patient safety $[66,67]$. Their differing methods meant it was initially uncertain which tool would be included in the PST; PC-SafeQuest was brief yet offered a useful cross-sectional assessment of safety culture [36] whereas the more resource intensive MaPSaF [35] was better placed to capture safety culture in its broadest form and explore practice specific perspectives [60].

Participants recognised the ability of both tools to promote and inform personal and team-based reflection on patient safety which led ultimately to the inclusion of both in the PST [68]. The anonymity of PC-SafeQuest meant honest opinions were aired and in the case of MaP$\mathrm{SaF}$ the use of a 'neutral' moderator mitigated imported hierarchies to the extent all felt free to express their opinions [69]. The reflective practice that both tools encouraged, i.e. the application of critical thinking to improve professional performance $[70,71]$ supports learning from experience, and aids decision-making in complex clinical settings $[72,73]$. Both tools also promoted reflexivity, the related process whereby individuals examine how their preconceptions, judgments and actions influenced how they fulfil their particular role [74]. Exercises promoting individual and group reflection have long been used in the education of providers in fields such as social care and psychology $[72,75]$ and are increasingly included in the curriculum of pharmacists [76] and medical students [77] suggesting that PC-SafeQuest or MaPSaF might also be employed as educational tools or in continuing professional development for primary care staff.

Primary care is increasingly reliant on a range of staff of different backgrounds, qualifications and experiences and both tools aimed to promote cross-practice collaboration in improving safety and their use was predicated on involving a range of clinical and non-clinical staff. They successfully raised the awareness of safety issues faced by colleagues in other areas that might otherwise have remained unidentified and such inter-professional insight has recently been recommended by the European
Forum for Primary Care for its ability to improve communication, and a team ethos and ultimately patient care $[78,79]$.

\section{Conclusions}

At the time of the study pressure on the UK primary care and in particular general practice was already increasing [80] and has since been exacerbated by the redesign of care processes and the working environment as a result of the Covid-19 pandemic [26]. Such mandatory, top-down changes run contrary to the widely understood principles of safe care which are based on broad stakeholder consultation and engagement [81-85] and highlights the importance of a resilient patient safety culture within practice organisations [86]. The tools studied here can gather relevant information on the major domains of patient safety culture in a reliable way through different approaches that allow individual practices to decide which suits them best at a particular point in time, dependent upon their current resources and priorities. It would appear that PC-SafeQuest's ability to enable a snapshot of safety culture without the logistical difficulties of convening multiple workshops is more suited for bigger practices employing large numbers of staff across multiple sites. By contrast MapSaf might be favoured by smaller practices where a moderated discussion involving the majority of the practice team can grant a more immediate shared understanding of the experiences of a range of staff groups.

\section{Abbreviations \\ PC - SafeQuest: Primary Care Safety Questionnaire; MapSaf: Manchester Patient Safety Framework; GP: General Practitioner; PST: Patient Safety Toolkit; UK: United Kingdom; NHS: National Health Service; RCGP: Royal College of General Practitioners; CCG: Clinical Commissioning Group; NIHR: National Institute for Health Research; CRN: Clinical Research Network.}

\section{Acknowledgements}

Not applicable.

\section{Authors' contributions}

IL was responsible for the methodology, writing the original draft and further reviews and editing, KM was responsible for data management, contributed to the original draft and subsequent reviews and editing; LD was responsible for data collection, contributed to the original draft and subsequent reviews and editing; KP contributed to the original draft and was responsible for further reviews and editing; AA was responsible for the study design and funding acquisition and the review and editing of subsequent drafts; SG was responsible for the study design and methodology, contributed to the original draft and further reviews and editing. All authors reviewed the manuscript before submission. The author(s) read and approved the final manuscript.

\section{Authors' information}

Not applicable.

\section{Funding}

The 'Development of the NSPCR Patient Safety Toolkit for general practices' was funded by the National Institute for Health Research School for Primary 
Care Research (NIHR SPCR). The funding body was neither involved in the design of the study nor the collection, analysis, and interpretation of data and writing of the manuscript.

\section{Availability of data and materials}

The datasets generated and analysed during the current study are not publicly available due to reason of participant confidentiality as explained in the manuscript but are available from the corresponding author on reasonable request.

\section{Declarations}

\section{Ethics approval and consent to participate}

This was obtained from East Midlands_Nottingham 1 Research Ethics Committee - REC/REF-13/EM/0258 15 July 2013 for all organisations involved. Informed consent was gained from all participants in line with the approval granted.

\section{Consent for publication}

Not applicable.

\section{Competing interests}

The author(s) declare(s) that they have no competing interests.

\section{Author details}

'Institute of Applied Health Research, College of Medical and Dental Sciences, University of Birmingham, Birmingham, UK. ${ }^{2}$ Division of Primary Care, School of Medicine, University of Nottingham, Nottingham, UK. ${ }^{3}$ Institute of Cancer and Genomic Sciences, College of Medical and Dental Sciences, University of Birmingham, Birmingham, UK. ${ }^{4}$ Alliance Manchester Business School, University of Manchester, Manchester, UK.

\section{Received: 23 November 2020 Accepted: 8 April 2021}

Published online: 21 May 2021

\section{References}

1. Flin R, Mearns K, O'Conner P, Bryden R. Measuring safety climate: identifying the common features. Saf Sci. 2000;34(1-3):177-92.

2. Agency IAE. Safety culture (safety series no. 75-INSAG-4).Vienna: International Atomic Energy Agency; 1991.

3. Glendon Al, Stanton NA. Perspectives on safety culture. Saf Sci. 2000;34:193-214.

4. Kapur N, Parand A, Soukup T, Reader T, Sevdalis N. Aviation and healthcare: a comparative review with implications for patient safety. JRSM Open. 2015;7(1):2054270415616548

5. Shaw J, Calder K. Aviation is not the only industry: healthcare could look wider for lessons on patient safety. Qual Saf Health Care. 2008;17(5):314.

6. Mannion R, Konteh FH, Davies HTO. Assessing organisational culture for quality and safety improvement: a national survey of tools and tool use. Qual Saf Health Care. 2008;18(2):153-6.

7. Guldenmund FW. The nature of safety culture: a review of theory and research. Saf Sci. 2000;34:215-57.

8. Flin R. Measuring safety culture in healthcare: a case for accurate diagnosis. Saf Sci. 2007:45:653-67.

9. Health \& Safety Executive. HSE human factors briefing note no. 7; safety culture 28 May 2015.

10. Seager L, Smith DW, Patel A, Brunt $H$, Brennan PA. Applying aviation factors to oral and maxillofacial surgery-the human element. Br J Oral Maxillofac Surg. 2013;51(1):8-13.

11. Catchpole KR, Dale TJ, Hirst DG, Smith JP, Giddings TA. A multicenter trial of aviation-style training for surgical teams. J Patient Saf. 2010;6(3):180-6.

12. Guldenmund FW. The nature of safety culture: a review of theory and research. Saf Sci . 2000;34(1):215-57.

13. Degani A, Wiener EL. Cockpit checklists: concepts design, and use. Hum Factors. 1993:35(2):345-59.

14. Clay-Williams R, Colligan L. Back to basics: checklists in aviation and healthcare. BMJ Qual Saf. 2015;24(7):428-31.
15. Sommer KJ. Pilot training: what can surgeons learn from it? Arab J Urol. 2014;12(1):32-5.

16. Kirk S, Parker D, Claridge T, Esmail A, Marshall M. Patient safety culture in primary care: developing a theoretical framework for practical use. Qual Saf Health Care. 2007;16(4):313-20.

17. Bowie P. Leadership and implementing a safety culture. Pract Nurse. 2010;40(10):32-5.

18. Finn R, Waring J. Ethnographic methods in patient safety. In: Walshe K, Boaden $\mathrm{R}$, editors. Patient safety: research into practice. Maidenhead: Open University Press; 2006.

19. Agency NPS. 7 steps to patient safety. 2004.

20. Gandhi TK, Lee TH. Patient safety beyond the hospital. N Engl J Med. 2010:363(11):1001-3.

21. Daker-White G, Hays R, McSharry J, Giles S, Cheraghi-Sohi S, Rhodes P, et al. Blame the patient, blame the doctor or blame the system? A metasynthesis of qualitative studies of patient safety in primary care. PLoS One. 2015;10(8):e0128329.

22. Dodds A, Kodate N. Accountability, organisational learning and risks to patient safety in England: conflict or compromise? Health Risk Soc. 2011:13(4):327-46.

23. Journal G. Covid-19 and the impact on general practice. 2020. https:// www.gmjournal.co.uk/covid-19-and-the-impact-on-general-practice.

24. England N. Standard operating procedure for for general practice in the context of coronavirus (COVID-19) 2020. Available from: https://www. england.nhs.uk/coronavirus/publication/managing-coronavirus-covid19-in-general-practice-sop/.

25. Practitioners RCoG. Latest COVID-19 guidance RCGP 2020. Available from: https://www.rcgp.org.uk/covid-19/latest-covid-19-guidance-in-your-area. aspx.

26. Digital N. Appointments in general practice 2020. Available from: https://digital.nhs.uk/data-and-information/publications/statistical/ appointments-in-general-practice/appointments-in-general-pract ice-supporting-information\#impact-of-coronavirus-on-gp-appoi ntment-data.

27. de Wet C, Bowie P, O'Donnell C. 'The big buzz': a qualitative study of how safe care is perceived, understood and improved in general practice. BMC Fam Pract. 2018;19(1):83.

28. Kaufman G, McCaughan D. The effect of organisational culture on patient safety. Nurs Stand (Royal College of Nursing (Great Britain): 1987). 2013;27(43):50-6.

29. Marshall M, Parker D, Esmail A, Kirk S, Claridge T. Culture of safety. Qual Saf Health Care. 2003;12(4):318. https://doi.org/10.1136/qhc.12.4.318-a.

30. Spencer R, Campbell S. Tools for primary care patient safety: a narrative review. BMC Fam Pract . 2014;15(1):166.

31. Mannion R, Konteh FH, Davies HTO. Assessing organisational culture for quality and safety improvement: a national survey of tools and tool use. Qual Saf Health Care. 2009;18(2):153-6.

32. Practitioners RCoG. Patient safety toolkit for general practice. Available from: http://www.rcgp.org.uk/clinical-and-research/patient-safety.aspx.

33. NIHR. School for Primary Care Research 2020. Available from: https:// www.spcr.nihr.ac.uk/.

34. Alsalem G, Bowie P, Morrison J. Assessing safety climate in acute hospital settings: a systematic review of the adequacy of the psychometric properties of survey measurement tools. BMC Health Serv Res. 2018;18(1):353.

35. Parker D. Managing risk in healthcare: understanding your safety culture using the Manchester Patient Safety Framework (MaPSaF). J Nurs Manag. 2009;17(2):218-22.

36. de Wet C, Spence W, Mash R, Johnson P, Bowie P. The development and psychometric evaluation of a safety climate measure for primary care. Qual Saf Health Care. 2010;19(6):578-84.

37. Proctor E, Silmere H, Raghavan R, Hovmand P, Aarons G, Bunger A, et al. Outcomes for implementation research: conceptual distinctions, measurement challenges, and research agenda. Adm Policy Ment Health. 2011;38(2):65-76.

38. Flin R, Burns C, Mearns K, Yule S, Robertson EM. Measuring safety climate in health care. Qual Saf Health Care. 2006;15(2):109.

39. Australian Commission on Safety and Culture in Health Care. Safety culture assessment in health care: a review of the literature on safety culture assessment modes. Sydney: Australian Commission on Safety and Quality in Health Care; 2017. 
40. Campbell SM, Bell BG, Marsden K, Spencer R, Kadam U, Perryman $\mathrm{K}$, et al. A patient safety toolkit for family practices. J Patient Saf. 2020;16(3):e182-6.

41. NIHR. Clinical Research Network 2020. Available from: https://www.nihr. ac.uk/explore-nihr/support/clinical-research-network.htm.

42. Palinkas LA, Horwitz SM, Green CA, Wisdom JP, Duan N, Hoagwood K. Purposeful sampling for qualitative data collection and analysis in mixed method implementation research. Adm Policy Ment Health. 2015;42(5):533-44.

43. Westrum R. A typology of organisational cultures. Qual Saf Health Care. 2004;13(suppl 2):ii22-7.

44. Institute E. Hearts and Minds Safety Culture Toolkit. Available from: https://heartsandminds.energyinst.org/.

45. Manchester Patient Safety Framework (MaPSaF). Manchester: University of Manchester; 2006. Available from: http://www.nrls.npsa.nhs.uk/resou rces/?entryid45 $=59796$.

46. Kitzinger J. Qualitative research. Introducing focus groups. BMJ. 1995;311(7000):299-302.

47. Bernard. Research methods in anthropology: qualitative and quantitative approaches. Walnut Creek: Altimira Press; 2017.

48. Kaiser K. Protecting respondent confidentiality in qualitative research. Qual Health Res. 2009;19(11):1632-41.

49. Hofmeyer AT, Scott CM. Moral geography of focus groups with participants who have preexisting relationships in the workplace. Int J Qual Methods. 2007;6(2):69-79.

50. Gupta R, Awasthy R, editors. Qualitative research in management: methods and experiences. 2015.

51. Kuckartz U. Qualitative text analysis: a systematic approach. In: Kaiser $\mathrm{G}$, Presmeg N, editors. Compendium for early career researchers in mathematics education. Cham: Springer International Publishing; 2019. p. 181-97.

52. Ilott I, Gerrish K, Booth A, Field B. Testing the consolidated framework for implementation research on health care innovations from South Yorkshire. J Eval Clin Pract. 2013;19(5):915-24.

53. Wisdom JP, Chor KHB, Hoagwood KE, Horwitz SM. Innovation adoption: a review of theories and constructs. Adm Policy Ment Health. 2014;41(4):480-502.

54. Sanson-Fisher RW. Diffusion of innovation theory for clinical change. Med J Aust. 2004;180(S6):S55-6.

55. Rogers EM. Diffusion of innovation. New York: New York Free Press; 1983.

56. Galesic M, Tourangeau R, Couper MP, Conrad FG. Eye-tracking data: new insights on response order effects and other cognitive shortcuts in survey responding. Public Opin Q. 2008;72(5):892-913.

57. Thornton J. Covid-19: how coronavirus will change the face of general practice forever. BMJ. 2020;368:m1279.

58. Sim J, Waterfield J. Focus group methodology: some ethical challenges. Qual Quant. 2019:53(6):3003-22.

59. Romney AK, Weller SC, Batchelder WH. Culture as consensus: a theory of culture and informant accuracy. Am Anthropol. 1986;88(2):313-38.

60. Esmail A. Measuring and monitoring safety: a primary care perspective. London: The Health Foundation; 2013.

61. Lydon S, Cupples ME, Murphy AW, Hart N, O’Connor P. A systematic review of measurement tools for the proactive assessment of patientsafety in general practice. J Patient Saf. 2017.https://doi.org/10.1097/PTS. 0000000000000350. Epub ahead of print.

62. Wachter RM. Patient safety at ten: unmistakable progress, troubling gaps. Health Aff (Project Hope). 2010;29(1):165-73.

63. NHS Improvement. The NHS patient safety strategy 2019. Available from: https://www.england.nhs.uk/patient-safety/the-nhs-patient-safety-strat egy/.

64. Verbakel NJ, Van Melle M, Langelaan M, Verheij TJM, Wagner C, Zwart DLM. Exploring patient safety culture in primary care. Int J Qual Health Care. 2014;26(6):585-91.

65. Ashcroft DM, Morecroft C, Parker D, Noyce PR. Safety culture assessment in community pharmacy: development, face validity, and feasibility of the Manchester Patient Safety Assessment Framework. Qual Saf Health Care. 2005;14(6):417-21.
66. ledema R. Creating safety by strengthening clinicians' capacity for reflexivity. BMJ Qual Saf. 2011;20(Suppl 1):i83-6.

67. Schippers MC, Den Hartog DN, Koopman PL, van Knippenberg DJHR. The role of transformational leadership in enhancing team reflexivity. Hum Relat. 2008;61(11):1593-616.

68. Litchfield I, Gill P, Avery T, Campbell S, Perryman K, Marsden K, et al. Influences on the adoption of patient safety innovation in primary care: a qualitative exploration of staff perspectives. BMC Fam Pract. 2018;19(1):72.

69. Litchfield I, Bentham L, Hill A, McManus RJ, Lilford R, Greenfield S. The impact of status and social context on health service co-design: an example from a collaborative improvement initiative in UK primary care. BMC Med Res Methodol. 2018;18(1):136.

70. Mamede S, Schmidt HG. The structure of reflective practice in medicine. Med Educ. 2004;38(12):1302-8.

71. Richard A, Gagnon M, Careau E. Using reflective practice in interprofessional education and practice: a realist review of its characteristics and effectiveness. J Interprof Care. 2019;33(5):424-36.

72. Mann K, Gordon J, MacLeod A. Reflection and reflective practice in health professions education: a systematic review. Adv Health Sci Educ Theory Pract. 2009;14(4):595-621.

73. Brandis S. "Pixie dust": the moderating effect of reflexivity on patient safety culture and quality patient care. J Health Organ Manag. 2019;33(5):635-46.

74. Brodsky A, Given LM Ed. The sage encyclopedia of qualitative research methods. Field notes. In L. Given (Ed.). 2008. p. 342-4.

75. Schippers MC, West MA, Dawson JF. Team reflexivity and innovation: the moderating role of team context. J Manag. 2015;41(3):769-88.

76. Pezzolesi C, Ghaleb M, Kostrzewski A, Dhillon S. Is mindful reflective practice the way forward to reduce medication errors? Int J Pharm Pract. 2013:21(6):413-6.

77. Ambrose LJ, Ker JS. Levels of reflective thinking and patient safety: an investigation of the mechanisms that impact on student learning in a single cohort over a 5 year curriculum. Adv Health Sci Educ Theory Pract. 2014;19(3):297-310.

78. Carney PA, Thayer EK, Palmer R, Galper AB, Zierler B, Eiff MP. The benefits of interprofessional learning and teamwork in primary care ambulatory training settings. J of Interprof Educ Pract. 2019;15:119-26.

79. Miller R, Scherpbier N, van Amsterdam L, Guedes V, Pype P. Inter-professional education and primary care: EFPC position paper. Prim Health Care Res Dev. 2019;20:e138.

80. Cogora. State of primary care. 2019.

81. Grimshaw JM, Thomas RE, MacLennan G, Fraser C, Ramsay CR, Vale L, et al. Effectiveness and efficiency of guideline dissemination and implementation strategies. Health Technol Assess (Winchester, England). 2004;8(6):iiiiv, $1-72$.

82. Foy R, Ovretveit J, Shekelle PG, Pronovost PJ, Taylor SL, Dy S, et al. The role of theory in research to develop and evaluate the implementation of patient safety practices. BMJ Qual Saf. 2011;20(5):453-9.

83. Johnson MJ, May CR. Promoting professional behaviour change in healthcare: what interventions work, and why? A theory-led overview of systematic reviews. BMJ Open. 2015;5(9):e008592.

84. Riley WT. Behavioral and social sciences at the National Institutes of Health: adoption of research findings in health research and practice as a scientific priority. Transl Behav Med. 2017;7(2):380-4.

85. McIntyre SA, Francis JJ, Gould NJ, Lorencatto F. The use of theory in process evaluations conducted alongside randomized trials of implementation interventions: a systematic review Transl Behav Med. 2018.

86. Walsh P. Saving lives threatened by COVID19 is rightly a priority, but many more can be saved by improving patient safety 2020. Available from: https://www.avma.org.uk/policy-campaigns/the-avma-blog/covi.

\section{Publisher's Note}

Springer Nature remains neutral with regard to jurisdictional claims in published maps and institutional affiliations. 